\title{
COMPARAÇÃO ENTRE O REAGENTE CHAGAS-LATEX E A IMUNO- FLUORESCÊNCIA NO DIAGNÓSTICO SOROLÓGICO DA DOENÇA DE CHAGAS NA ZONA SUL DO RIO GRANDE DO SUL *
}

\author{
Giovanni Baruffa ${ }^{* *}$ e Alcino Alcantara Filho ***
}

\begin{abstract}
Os Autores submeteram 142 amostras de soros de casos agudos e crônicos de Doença de Chagas, já examinados com o Reagente Chagas-Latex, ao exame de Imunofluorescência, obtendo correspondência de resultados em 139 (97,9\%). $\mathrm{O}$ alto indice de fidelidade, provavelmente devido à ausência na zona de doenças que possam proporcionar resultados falsamente positivos, fez do Reagente Chagas-Latex um método simples e fácil para a triagem sorológica nos casos suspeitos em zona endêmica.
\end{abstract}

\section{INTRODUÇÃO}

O Reagente Chagas-Latex é constituído de uma suspensão de partículas de polistireno, às quais estão aderidos antígenos específicos de Trypanosoma cruzi. O seu emprego extremamente fácil e a grande simplicidade e rapidez de execução da reação fazem-no indicado para triagem sorológica de casos suspeitos de Doença de Chagas tanto em ambiente hospitalar quanto em condições de campo.

\section{MATERIAL E MÉTODO}

Desde julho de 1970 temos em andamento um inquérito sorológico destinado a estabelecer a prevalência da Doença de Chagas em populações rurais, sem seleção prévia, na Zona Sul do Rio Grande do Sul. No ano de 1972 colhemos 1051 amostras de 4 Municipios da Zona Sul (Herval do Sul, Lavras do Sul, Caçapava do Sul e Pelotas). Com exceção de 10 amostras que não puderam ser aproveitadas por várias causas (material insuficiente, extravio, contaminação etc.), em 1041 foi utilizado, para o diagnóstico sorológico da Doença de Chagas, o Reagente ChagasLatex, gentilmente fornecido pelo Laboratório Hoechst do Brasil. O índice de prevalência para a Doença de Chagas nas 1041 amostras foi de $18,8 \%$, com valores máximos de $38,0 \%$ no Município de $\mathrm{Ca}-$ çapava e valores mínimos de $9,5 \%$ no $\mathrm{Mu}-$ nicipio de Pelotas. Os índices obtidos correspondiam às nossas expectativas e pouco se afastavam daqueles obtidos em áreas contíguas através de inquéritos anteriores por nós realizados e nos quais empregamos a fixação de complemento $(44,4 \%$ no Município de Santana da Boa Vista, contíguo e com as mesmas características fisiográficas e sócio-econômicas do Municí-

* Trabalho realizado pela Cadeira de Doenças Infecciosas e Parasitárias da Fac. Med. da Universidade Católica de Pelotas (R.S.).

** Prof. Titular da Cadeira de Doenças Infecciosas e Parasitárizs.

** Prof. Adjunto do Depto. de Morfologia.

Recebido para publicação em 10.6.73. 
pio de Caçapava e $13,6 \%$ no Município de Pedro Osório, contíguo e com características semelhantes ao Município de Pelotas) (1).

Com a finalidade de averiguar a concordância entre o Reagente Chagas-Latex e a Imunofluorescência, realizamos em 3 grupos de amostras de soros, já posit vos ao Reagente Chagas-Latex, a reação de Imunofluorescência. A prozedência dos 3 grupos de amostras era a seguinte:

- 69 obtidas no mencionado inquérito de campo;

- 49 obtidas de 48 pacientes internados no Departamento de Clínica Médica da Faculdade de Medicina da Universidade Católica de Pelotas (Santa Casa de Misericórdia). A maioria dos pacientes era portadora de quadros clínicos compatíveis com patías chagásicas crônicas conforme especificado:

Forma cardíaca ............. 15

Forma card. dig. ............ 12

Forma digest. . . . . . . . . . 10

Forma ind. ............... 11

Total . . . . . . . . . . . . . 48

- 24 obtidas de 10 casos agudos, hospitalizados. Nestes casos a retirada das amostras se deu ou na vigência da fase aguda, ou em posterior internação para controle de ensaio quimioterápico. Das 24 amostras deste grupo, 22 eram positivas ao Reagente Chagas-Latex e 2 nfgativas. Todos os casos agudos foram comprovados pelo encontro do Trypanosoma cruzi no sangue periférico.

Os resultados comparativos entre a resposta ao Reagente Chagas-Latex e à Imunofluorescência nas 142 amostras estudadas estão sumarizados na Tab. I.

\section{CONSIDERAÇÓES}

Como se deduz da tabela I, de 142 amostras examinadas, 140 foram positivas ao Reagente Chagas-Latex e só 2 negativas. As 2 negativas se referiam a um caso agudo, tratado um ano antes com quimioterápico (Bayer 2502).

Analisando o comportamento da Imunofluorescência nos 3 grupos de amostras observamos

19 - no grupo de 69 amostras do inquérito de campo, todas positivas ao Reagente Chagas-Latex, 68 resultaram positivas à Imunofluorescência;

29 - no grupo de 49 amostras oriundas de casos crônicos hospitalares, todas positivas ao Latex, 47 resultaram positivas à Imunofluorescência;

39 - no grupo de 24 amostras de casos agudos, 22 das quais eram positivas ao Latex, a correspondência com a Imunofluorescência foi de $100 \%$.

TABELA I

Relação entre Reação Chagas-Latex e de Imunofluorescência em casos de doença de Chagas.

\begin{tabular}{|c|c|c|c|c|c|}
\hline \multirow{2}{*}{$\begin{array}{l}\text { Procedência das } \\
\text { amostras }\end{array}$} & \multirow{2}{*}{$\begin{array}{c}\text { No de } \\
\text { Reações }\end{array}$} & \multicolumn{2}{|c|}{ LATEX } & \multicolumn{2}{|c|}{$\begin{array}{l}\text { IMUNOFLUORES- } \\
\text { CENACIA }\end{array}$} \\
\hline & & Pos. & Neg. & Pos. & Neg. \\
\hline 69 de inquérito de campo .. & 69 & 69 & - & 68 & 1 \\
\hline 48 casos crônicos & 49 & 49 & - & 47 & 2 \\
\hline 10 casos agudos & 24 & 22 & 2 & 22 & 2 \\
\hline Total . . ............. & 142 & 140 & 2 & 137 & 5 \\
\hline
\end{tabular}


Só em 3 amostras de 142, portanto, não houve correspondência entre o Reagente Chagas-Latex e a Imunofluorescência .. $(2,1 \%)$.

Achamos oportuno um breve comentário sobre as 2 amostras procedentes de um dos casos crônicos hospitalares, positivas ao Latex e que resultaram negativas à Imunofluorescência: 2 amostras pertenciam a uma paciente de 39 anos, procedente de zona endêmica, e com manifestações cardíacas (bloqueio completo de ramo direito) e digestivas (megaesôfago grau 2 e megasigmoide), sugestivas de etiologia chagásica. A paciente foi encaminhada à cirurgia por megasigmoide, tendo realizado antes da intervenção o exame sorológico com Antígeno Chagas-Latex e a Imunofluorescência, que resultaram, respectivamente, positivo e negativa. A repetịção de ambos os exames após a cirurgia confirmou os resultados antoriores. A histopatologia da peça operatória revelou-se compatível com mega chagásico (atrofia muscular, infiltrado linfoplasmocitário com discreto número de eosinófilos, redução das células ganglionares dos plexos de Meissner e Auerbach etc.). Neste caso a soma dos elementos epidemiológicos, anatomopatológicos nos faz propender em aceitar como válida a resposta positiva ao Reagente Chagas-Latex, não obstante a negatividade da Imunofluorescênc:a.

Achamos interessante assinalar um outro caso, que não consta da presente resenha e no qual houve disparidade de resultados entre antígeno Chagas-Latex e Imunofluorescência. Tratava-se de uma criança recém nascida, de sexo feminino, filha de mãe chagásica (Latex e Imunofluorescência positivos). Nesta recém nascida realizamos exame soro'ógico com Reagente Chagas-Latex e a Imunofluorescência aos 3 e aos 18 dias de vida com os seguintes resultados: Latex fortemente positivo em ambos os exames e Imunofluorescência sempre negativa. No caso a positividade ao Latex estava provavelmente relacionada com a passagem de anticorpos maternos através da placenta. Como no caso referido anteriormente, também aqui não temos explicação para a negatividade da Imunofluorescência.

Para finalisar, achamos o Reagente Chagas-Latex um método de triagem útil e válido tanto em pesquisas de campo como em ambiente hospitalar. O Reagente, a nosso ver, pode ser usado com tranqüilidade em consideração da pequena, (e discutivel na nossa casuística), margem de discordância apresentada com respeito à Imunofluorescência. Nāo pretendemos absolutamente generalizar esta nossa afirmação, que pode ser válida em situações, como é o nosso caso, onde estão ausentes malária, calazar, pênfigo foliáceo, etc., que podem provocar resultados falsamente positivos em parcela substancial de soros, quando presentes em situação endêmica (2).

\section{AGRADECIMENTO}

Agradecemos ao Sr. Neide Manfrin, laboratorista da Sucam, pela inestimável colaboração prestada realizando todas as Imunofluorescências.

\section{SUMMARY}

142 serum samples from acute and chronic Chagas Disease, diagnosed by Chagas-Latex Reagent, were examined by Imunofluorescence. Results of both Imunofluorescence and Chagas-Latex were in concordance in $139(97,9 \%)$. The high concordance rate between the two technics, probably depending from the absence in the region of endemic diseases causing false positive results, leads to the conclusion that Chagas-Latex Reagent is a simple and easy test for sorological trials in endemic Chagas Disease area. 


\section{REFERÊNCIAS BIBLIOGRÁFICAS}

1. BARUFFA, G.; AQUINO NETO, J. O.; ALCANTARA, F. A.; BETTIN, W. N. \& BERTINETTI, E. S. - Dados preliminares de inquérito sorológico e eletrocardiográfico para Doença de Chagas em populaçōes rurais não selecionadas da Zona Sul do Rio Grande do. Sul. Comunicação ao VIII Congresso da Soc. Bras. de Med. Trop.
Belo Horizonte, 6-9 de Fevereiro, 1972.

2. PRATA, A. et Al. - Estudo sobre a prova de Látex para diagnóstico imunológico da Doença de Chagas. Ensaio de campo realizado em oito centros de investigaçâo sobre Doença de Chagas. - Dados distribuidos pela Hoechst do Brasil. 